\title{
Glycoprotein Requirement for Neurite Outgrowth in Goldfish Retina Explants: Effects of Tunicamycin
}

\author{
ANNE M. HEACOCK \\ Neuroscience Laboratory, University of Michigan, Ann Arbor, MI 48109 (U.S.A.)
}

(Accepted November 3rd, 1981)

Key words: glycoproteins - lectins — dolichol - tunicamycin -- neurites - neuronal recognition

\begin{abstract}
The role of glycoproteins in neurite outgrowth in vitro has been examined using the protein glycosylation inhibitor, tunicamycin. The concentration-dependent inhibitory effects of tunicamycin on neuritic outgrowth from goldfish retinal explants closely paralleled its effects on the dolichol pathway of glycoprotein biosynthesis. The neurite membrane assembled in the presence of an intermediate dose of tunicamycin $(5 \mu \mathrm{g} / \mathrm{ml})$ was deficient in carbohydrate, as indicated by a reduced capacity to bind the lectins Concanavalin A, wheat germ agglutinin and ricin. These results suggest that tunicamycin may prove useful in assessing the role of cell surface carbohydrate in neuronal recognition phenomena.
\end{abstract}

\section{INTRODUCTION}

Although glycoproteins are major constituents of plasma membranes, including axonal membranes, little is known about their function. Speculation has included possible roles for cell surface carbohydrates in neuronal recognition, synaptogenesis and ligand-receptor interactions ${ }^{2,29}$. Assessment of the functional significance of glycoproteins has been aided by studies on their structure and biosynthesis and by the discovery of a specific inhibitor of the latter. The majority of the protein-bound carbohydrate in brain, as well as in other tissues, is linked via $\mathrm{N}$-acetylglucosamine residues to the amide nitrogen of asparagine and contains a mannose-rich inner core region ${ }^{21}$. This core oligosaccharide is assembled (Fig. 1) while bound to a lipid carrier, dolichol pyrophosphate, then subsequently attached to protein ${ }^{37}$. Membrane preparations from calf brain $^{36}$ and chick or bovine retinas ${ }^{5,16}$ have been shown to carry out the reactions of the dolichol pathway. The antibiotic tunicamycin has been found to inhibit protein glycosylation by blocking the first step in this pathway ${ }^{34,35}$. The availability of this inhibitor offers the opportunity to examine the glycoprotein requirement of various neuronal functions.
Prior studies of lectin binding to regenerating goldfish optic nerve, using retinal explants as an in vitro model, indicated the presence of mannose and $\mathrm{N}$-acetyl glucosamine residues on the axolemma of the growing neurites ${ }^{9,10}$. Since these two carbohy-

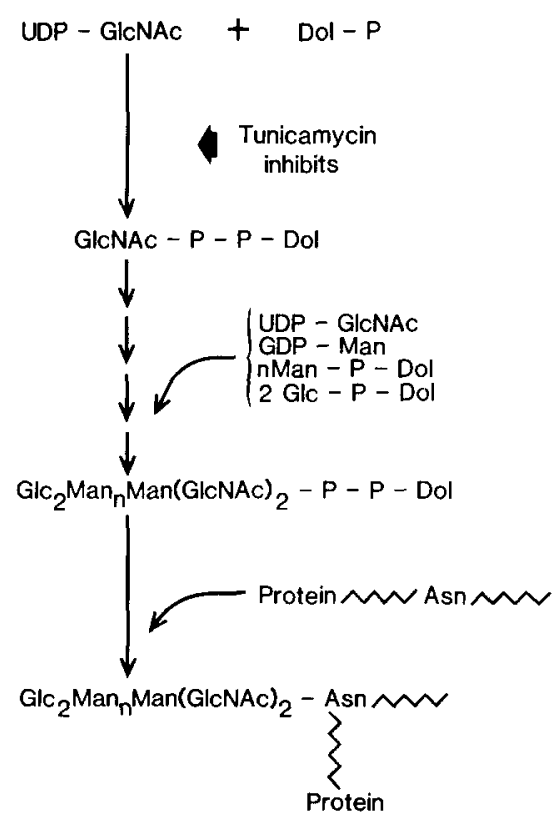

Fig. 1. Schematic of dolichol pathway of core oligosaccharide synthesis. Dol-P, dolichol phosphate; UDP, uridine diphosphate; GlcNAc, N-acetylglucosamine; GDP, guanosine diphosphate; Man, mannose; Glc, glucose; Asn, asparagine. 
drates are components of the core oligosaccharide. tunicamycin might be expected to interfere with their appearance at the neurite cell surface. This report demonstrates that the neuritic membrane elaborated in the presence of tunicamycin has a reduced lectin binding capacity. In addition, tunicamycin was found to inhibit neuritic outgrowth in a concentration-dependent manner which could be correlated with the metabolic effects of the antibiotic. Part of this work has been presented in a preliminary form ${ }^{11,12}$.

\section{MATERIALS AND METHODS}

\section{Explant preparation}

Retinas were removed from goldfish (Carassius auratus, 7-11 g, Ozark Fisheries) at 10-14 days following optic nerve crush, explanted as previously described ${ }^{17}$ onto polylysine coated plastic dishes or glass coverslips ${ }^{13}$ and maintained at $20-22{ }^{\circ} \mathrm{C}$ in humid chambers. Tunicamycin (gift of G. Tamura, or of R. Hamill, Eli Lilly) was stored at $-20^{\circ} \mathrm{C}$ as a stock solution of $200 \mu \mathrm{g} / \mathrm{ml}$ in $0.025 \mathrm{~N} \mathrm{NaOH}$. (Although not used for these experiments, tunicamycin purchased from Calbiochem had effects similar to those described here.) Prior to use, the stock solution was diluted with L-15 tissue culture medium (Gibco) to give a final concentration of $1-10$ $\mu \mathrm{g} / \mathrm{ml}$. The resulting solution was filter sterilized before addition to the culture dishes. After 6 days in culture, the extent of neuritic outgrowth was estimated ${ }^{18}$. Briefly, the average length of the neurites. in units of $500 \mu \mathrm{m}$, was multiplied by an estimate of the neuritic density, on an arbitrary scale of $1-4$, to give a nerve growth index (NGI). For each experimental group, 3 dishes, each containing 16 explants, were scored.

\section{Lectin binding}

The rhodamine-labeled lectins, Concanavalin A (Con A), wheat germ agglutinin (WGA) and ricin (RCA I) were purchased from Vector Laboratories. The lectins were diluted to $25-200 \mu \mathrm{g} / \mathrm{ml}$ in phosphate-buffered saline ${ }^{6}$ (PBS) prior to use. Cultures were grown on no. $11 / 2$ glass coverslips in either control medium or medium containing $5 \mu \mathrm{g} / \mathrm{ml}$ tunicamycin. The latter was added at day 2 of culture in order to permit sufficient growth to prevent detachment of the explants during the subsequent rinses and incubations with lectin. After 6 days in vitro (4 days exposure to tunicamycin), cultures were rinsed 3 times with. PBS, incubated with lectin solution for 30 min at room temperature. rinsed again, then examined by fluorescence microscopy (Leitz Diavert). There was no binding of Con $A$. WGA and RCA $I$ in the presence of their respective competing sugars, $t-i n e t h y l$ mannoside $(50 \mathrm{mM}), \mathrm{N}, \mathrm{N}^{\prime}, \mathrm{N}^{\prime \prime}$-triacetylchitotriose $(20 \mathrm{mM})$ and lactose $(50 \mathrm{mM})$. The lipophilic fluorescent dye. 3.3 . dioctadecylindocarbocyanine (dil) was a gift of $D$. Axelrod (University of Michigan:

\section{Precursor incorporation}

Control or tunicamycin-treated cultures were incubated, with or without tunicamycin, in fresh medium with $20 \mu \mathrm{Ci} / \mathrm{ml}$ of either $\mathrm{D}-\left[6{ }^{3} \mathrm{H}(\mathrm{N})\right]$ glucosamine hydrochloride (New England Nuclear, 19 $\mathrm{Ci} / \mathrm{mmol}$ ), D-[2-3 $\mathrm{H}]$ mannose Amersham. 12 $\mathrm{Ci} / \mathrm{mmol}$ ) of $1 .-\left[2,3{ }^{3} \mathrm{H}\right]$ proline (New England Nuclear, $23.7 \mathrm{Ci} / \mathrm{mmol}$ ). Protein-bound radioactivity was determined by a modification of the TCA-filter paper method of Mans and Novelli20. followed by solubilization with Soluene (Packard). Protein was determined spectrophotometrically ${ }^{19}$.

For incorporation experiments with intact retinas, the incubation medium of Dunlop et al. ${ }^{7}$. with 10 $\mathrm{mM}$ pyruvate substituted for glucose, was used. Retinas could be incubated in this medium at $20^{\circ} \mathrm{C}$ under $95 \% \mathrm{O}_{2} / 5 \% \mathrm{CO}_{2}$ for at least $6 \mathrm{~h}$ with no loss of their ability to incorporate labeled amino acids or sugars into protein. Retinas were routinely preincubated in the presence or absence of tunicamycin for $+6 \mathrm{~h}$. then transferred to fresh medium, - tunicamycin, with the appropriate radioactive precursor and incubated for a further $60 \mathrm{~min}$. Incorporation, which was linear throughout this time, was stopped by dilution with 20 vols. ice-cold saline. Retinas were then either frozen over dry-ice and stored at

20 C prior to analysis, or homogenized immediately in groups of 3 or 4 in $0.4 \mathrm{ml} \mathrm{H}_{2} \mathrm{O}$. Aliquots

Fig. 2. Inhibition of neurite outgrowth by tunicamycin. Dark-field (a-d) and phase $(e-h)$ photomicrographs of explants exposed io the following concentrations of tunicamycin for 6 days: $0 \mu \mathrm{g} / \mathrm{ml}(\mathrm{a}, \mathrm{e}) ; 1 / \mathrm{g} / \mathrm{ml}(\mathrm{b}, \mathrm{f}): 5 / \mathrm{g} / \mathrm{ml}(\mathrm{c}, \mathrm{g}) ; 10 / / \mathrm{g} m /(\mathrm{d}, \mathrm{h}) \mathrm{Bat}=200 / \mathrm{m}$ 

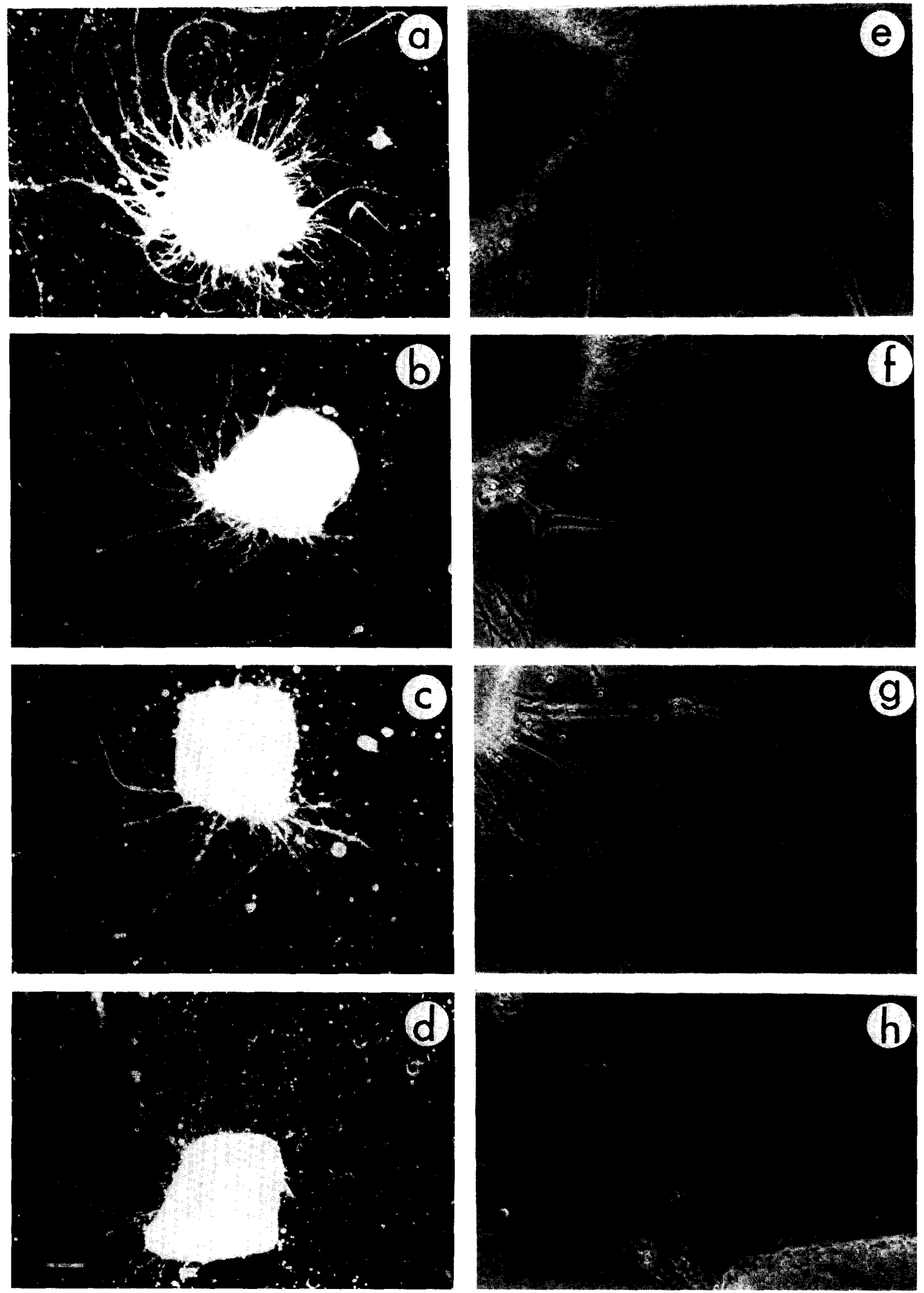
were removed for the TCA-filter paper assay and protein determination. The remainder was sequentially extracted with chloroform:methanol $(1: 1)$ and chloroform:methanol:water (10:10:3) as described by Schmitt and Elbein 28 to isolate dolichol monosaccharides and dolichol oligosaccharides, respectively. Mild acid hydrolysis was carried out as described by Chambers et al. ${ }^{4}$. For gel electrophoresis, retinas labeled with $\left[{ }^{3} \mathrm{H}\right]$ glucosamine or $\mathrm{L}-[4,5$ ${ }^{3} \mathrm{H}$ ]leucine (New England Nuclear, $60 \mathrm{Ci} / \mathrm{mmol}$ ). were homogenized in $0.0625 \mathrm{M}$ Tris $-\mathrm{HCl}, \mathrm{pH} 6.8$. then brought to a final concentration of $2 \%$ in SDS and $8 \mathrm{M}$ in urea. Insoluble material was removed by centrifugation at $100,000 \times g$ for $120 \mathrm{~min}$. Slab gel electrophoresis ( $10 \%$ polyacrylamide) was carried out as described by $\mathrm{O}^{\prime}$ Farrell ${ }^{22}$ and the protein labeling pattern was examined following fluorography:.

\section{RESULTS}

\section{Effects on neurite growth}

Goldfish retinal explants were cultured for 6 days in the presence of $0-10 \mu \mathrm{g} / \mathrm{ml}$ tunicamycin, at which time the extent of neurite outgrowth was estimated. Dark-field and phase photomicrographs of representative cultures are shown in Fig. 2. Control explants (Fig. 2a. e) exhibited a neuritic growth index (NGI) of $5.22+0.74$ (mean 1 S.D., $n$ 144). Tunicamycin at 1,5 or $10 \mu \mathrm{g} / \mathrm{ml}$ (Fig. $2 \mathrm{~b}-\mathrm{d}$. $f-h)$ inhibited neurite outgrowth by 31,63 and $85^{\circ} \%$, respectively $(P \quad 0.05)$. The inhibitory effects of

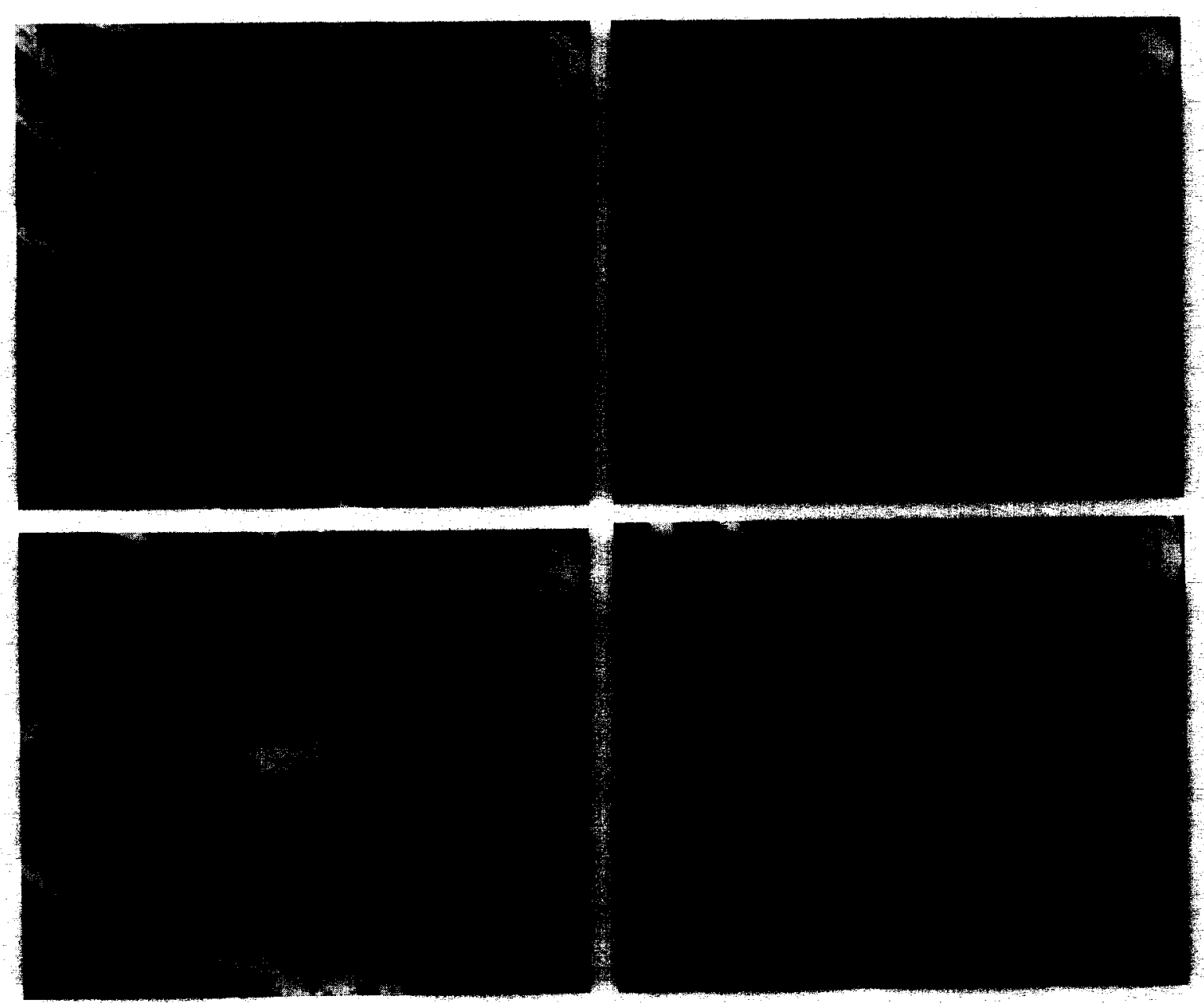

Fig. 3. Effect of tunicamycin $(5 \mu \mathrm{g} / \mathrm{ml})$ on binding of fluorescent markers to retinal explant neurites. Fluorescence photomicregraphs of control $(a, c)$ and tunicamycin-treated $(b, d)$ neurites labeled with rhodamine Con $A(a, b)$ or the lipophilic dye, dil (c, d). Bar $=100 \mu \mathrm{m}$. 
tunicamycin could be reversed if the antibiotic was removed from the medium. Cultures exposed to tunicamycin $(5 \mu \mathrm{g} / \mathrm{ml})$ for $24 \mathrm{~h}$, from day 2 to day 3 of explantation, exhibited, at day 6, an NGI only $14 \%$ below control values.

\section{Effects on lectin binding}

Neurites which grew out in the presence of 10 $\mu \mathrm{g} / \mathrm{ml}$ tunicamycin appeared to be deteriorating, but with lower doses, the neurites, although shorter and less abundant, seemed normal in morphology. To determine if their surface glycoprotein content had been altered, fluorescent lectin binding experiments were carried out. It had previously been shown that the retinal explants neurites contain receptors for Con A, WGA and RCA, indicating the presence of mannose, $\mathrm{N}$-acetyl glucosamine (or sialic acid) and galactose, respectively, on the neurite membrane ${ }^{10}$. Tunicamycin treatment $(5 \mu \mathrm{g} / \mathrm{ml})$ was found to decrease the binding of Con $\mathrm{A}$ (Fig. $3 \mathrm{a}, \mathrm{b}$ ) and to have similar effects on WGA and RCA. This reduction in lectin binding did not occur with other agents that inhibit neurite outgrowth such as the cholesterol synthesis inhibitor, diazacholesterol ${ }^{11}$. Some indication that the tunicamycin-induced reduction was specific for lectin receptors was obtained by examining the binding of the lipophilic dye, diI. This fluorescent probe intercalates into the plasma membrane and can give an estimate of the membrane

\section{TABLE ।}

Effects of tunicamycin on protein and glycoprotein synthesis in retinal explants

On day 6 of culture, explants were preincubated with tunicamycin $(5 \mu \mathrm{g} / \mathrm{ml})$ for $16 \mathrm{~h}$, then incubated in fresh medium containing tunicamycin with $10 \mu \mathrm{Ci} / \mathrm{ml}$ of $\left[{ }^{3} \mathrm{H}\right]$ glucosamine, $\left[{ }^{3} \mathrm{H}\right]$ mannose or $\left[{ }^{3} \mathrm{H}\right]$ proline for $4 \mathrm{~h}$. TCA precipitable radioactivity was determined and compared with that of control cultures not exposed to tunicamycin. Three culture dishes were pooled for each analysis. Data are expressed as $\mathrm{dpm} / \mu \mathrm{g}$ protein $t$ S.D. $(n=4)$.

\begin{tabular}{lrrr} 
& Control & Tunicamycin \\
\hline$\left[{ }^{3} \mathrm{H}\right]$ glucosamine & $516 \pm 88$ & $271 \pm 30^{*}$ \\
{$\left[{ }^{3} \mathrm{H}\right]$ mannose } & $106 \pm 13$ & $48 \pm 10^{*}$ \\
{$\left[{ }^{3} \mathrm{H}\right]$ proline } & $4903 \pm 319$ & $4273 \pm 253^{* *}$
\end{tabular}

* Significantly different from control at $P<0.005$ (Student's $t$-test).

** Significantly different from control at $P<0.025$.

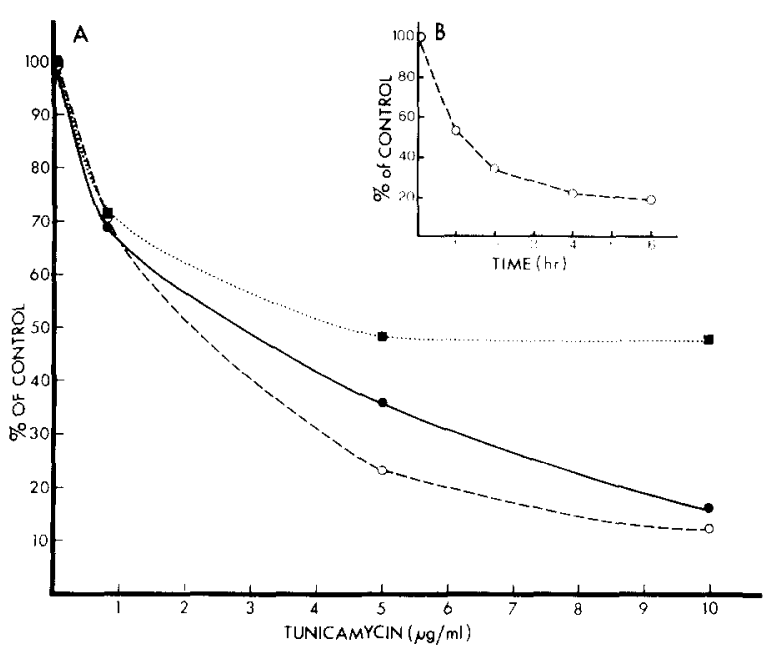

Fig. 4. Concentration dependence (A) and time course (B) of the effects of tunicamycin on explant neurite outgrowth (O), and on whole retina glycoprotein synthesis $(\square)$ or dolichol oligosaccharide synthesis ( ). Data are expressed as $\%$ of the following control values ( \pm S.D.): neurite outgrowth (NGI) $=5.22 \pm 0.74 ;$ glycoprotein synthesis $=76,370 \pm 5200$ $\mathrm{dpm} /$ retina; dolichol oligosaccharide synthesis $\ldots 10,780 \pm$ $1510 \mathrm{dpm} /$ retina. Each point in A represents the mean of determinations from 3 separate experiments, each carried out in triplicate. For the single experiment on $\mathrm{B}, 5 \mu \mathrm{g} / \mathrm{ml}$ of tunicamycin was used. All tunicamycin-treated values were significantly different from control at the $P \quad 0.05$ level.

surface area ${ }^{1}$. When labeled with dil, the control and tunicamycin-treated neurite membranes could not be distinguished from each other (Fig. 3c, d).

\section{Effects on incorporation of labeled precursor}

The effects of tunicamycin on glycoprotein and protein synthesis were then examined (Table I). Following exposure to $5 \mu \mathrm{g} / \mathrm{ml}$ tunicamycin, the incorporation of $\left[{ }^{3} \mathrm{H}\right]$ glucosamine and $\left[{ }^{3} \mathrm{H}\right]$ mannose into protein was inhibited 47 and $54 \%$, respectively. At this same concentration of the antibiotic, protein synthesis, as measured by $\left[{ }^{3} \mathrm{H}\right]$ proline incorporation, declined by only $13 \%$. No inhibition of glycoprotein synthesis was seen if a tunicamycin preincubation of only 30 min was used, in agreement with previous reports of a lag period before maximal effects of the drug were manifested in other cultured cells $^{33}$. The lack of inhibition after brief pretreatment argues against a direct effect of tunicamycin on uptake of labeled precursor into the explants. These observations suggest that the functioning of the dolichol pathway is required for retinal glycoprotein synthesis and that neurite elongation is inhibited 

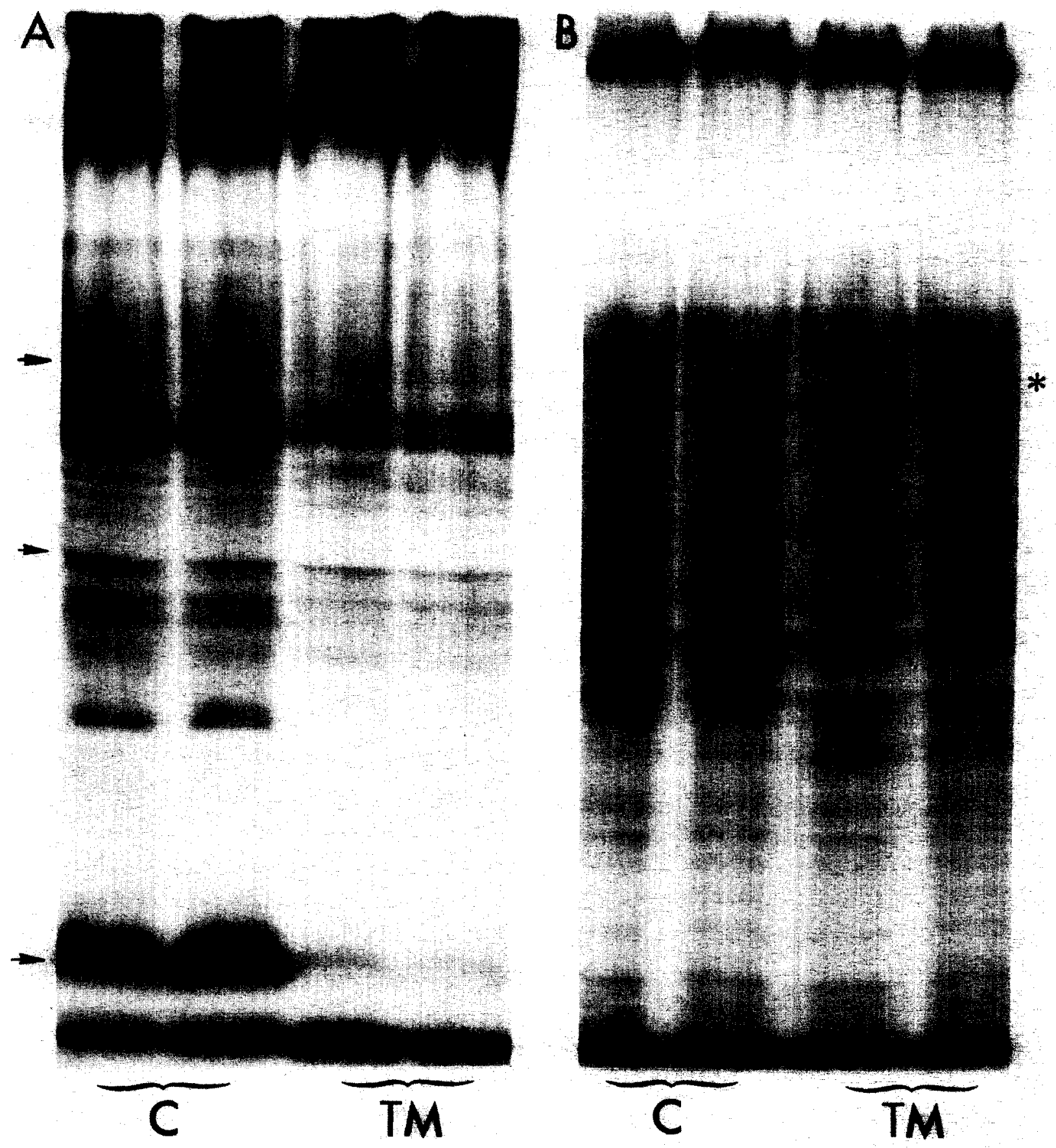

Fig. 5. Effect of tunicamycin on retina SDS gel pattern. Fluorography of $\left[{ }^{3} \mathrm{H}\right]$ glucosamine $(A)$ or $\left[{ }^{3} \mathrm{H}\right]$ leucine $(\mathrm{B})$ labeled proteins from control (C) or tunicamycin (TM, $5 \mu \mathrm{g} / \mathrm{ml}$ ) treated retinas. In each panel, the same amount of protein-bound radioactivity was applied to each lane. The average specific radioactivity of the TM-treated $\left[{ }^{3} \mathrm{H}\right]$ glucosamine-labeled proteins was $55 \%$ of control, while that of the TM-treated [ ${ }^{3} \mathrm{H}$ ]leucine-labeled proteins was $86 \%$ of control. Arrows indicate the positions of the molecular weight standards, bovine serum albumin $(68,000)$, ovalbumin $(45,000)$ and ribonuclease $(14,000)$.

when protein glycosylation is inhibited.

Direct demonstration of the effects of tunicamycin on the dolichol sugar pathway in the retinal explants was not practical due to the small amount of tissue available. For this reason, further studies were carried out using intact goldfish retinas incubated in vitro. Following incubation of retinas with $\left.{ }^{3} \mathrm{H}\right]$ glucosamine for $1 \mathrm{~h}$, approximately $80^{\circ}$, of the 
incorporated radioactivity was found in the glycoprotein fraction, while in the lipid-extractable fractions, non-dolichol glycolipids (including gangliosides) accounted for $4.8 \%$, dolichol monosaccharides $1.2 \%$, and dolichol oligosaccharides $14 \%$ of the total incorporation. Radioactivity in the lipid-sugar fractions was distinguished from that in gangliosides by lability to weak acid hydrolysis. All of the chloroform:methanol:water (10:10:3) fraction (containing dolichol oligosaccharides) was made water soluble by this treatment, while in the chloroform:methanol (1:1) extract (containing dolichol monosaccharides and gangliosides) only $20 \%$ was acid labile, corresponding to the fraction of radioactivity in $\mathrm{N}$-acetyl glucosaminylpyrophosphoryl-dolichol. The identity of the dolichol oligosaccharide was further supported by its chromatographic behavior on DEAEcellulose ${ }^{36}$ and by its ability to incorporate $\left[{ }^{3} \mathrm{H}\right]-$ mannose.

The concentration dependence of the effects of tunicamycin on retina glycoconjugate synthesis was then examined and compared with that for neurite outgrowth inhibition (Fig. 4a). Preincubation of retinas with 5 or $10 \mu \mathrm{g} / \mathrm{ml}$ tunicamycin resulted in inhibition of $\left[{ }^{3} \mathrm{H}\right]$ glucosamine incorporation into glycoprotein to an extent similar to that observed with the retinal explants. The remaining $50 \%$ of the labeling which was resistant to tunicamycin is most likely due to the incorporation of $\left[{ }^{3} \mathrm{H}\right]$ glucosamine into O-linked glycoproteins or into pre-existing glycoprotein at a step beyond core oligosaccharide synthesis. Effects of tunicamycin on the immediate precursor of the latter, dolichol oligosaccharide, were much more dramatic and closely paralleled neurite outgrowth inhibition. The maximum reduction in dolichol oligosaccharide was obtained after 4-6 h preincubation with a given dose of tunicamycin (Fig. 4b). The latter did not inhibit uptake of the precursor or of the total chloroform:methanol (1:1) fraction although the radioactivity in the acid labile component of this extract was reduced to $40 \%$ of control. Incorporation of $\left[{ }^{3} \mathrm{H}\right]$ mannose into glycoprotein and dolichol oligosaccharide in the presence of tunicamycin was inhibited to the same

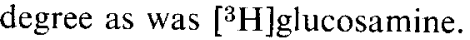

\section{Effects on SDS gel electrophoretic pattern}

In order to determine if tunicamycin was inhibi- ting the synthesis of any particular glycoprotein(s), SDS gel electrophoresis of $\left[{ }^{3} \mathrm{H}\right] \mathrm{glucosamine}$ or $\left[{ }^{3} \mathrm{H}\right]$ leucine-labeled retinal proteins was carried out. The same amount of protein-bound radioactivity was applied to each lane in order to more clearly visualize any changes in the relative pattern of labeling. The most striking effect in the $\left[{ }^{3} \mathrm{H}\right]$ glucosamine gels (Fig. 5A) was the absence in the tunicamycintreated retinas of a heavily labeled band moving just behind the dye front, comigrating with a 14,000 molecular weight protein standard. This material is most likely dolichol oligosaccharide, since it was absent in chloroform:methanol :water-treated samples. All of the other bands were of similar relative intensity except for a band in the 30,000 molecular weight area. Tunicamycin appears then, at this level of resolution, to decrease the amount of carbohydrate incorporated into protein and not to grossly alter the pattern of glycoproteins made by the retina. The gel electrophoretic profiles of proteins labeled by $\left[{ }^{3} \mathrm{H}\right]$ leucine in control and tunicamycin-treated retinas were also similar except for a novel band in the latter (Fig. 5B, asterisk). The altered migration of this protein may be due to a change in its state of glycosylation.

\section{DISCUSSION}

Evidence is accumulating in support of the postulated role of oligosaccharides as carriers of biological information (for reviews see refs. 29, 30). The heterogeneity of glycoproteins resides not only in the type and sequence of sugar residues but also in the nature of the linkages present and the occurrence of branch points. Thus, glycoproteins have much more potential for structural diversity than proteins or nucleic acids. While in some systems it has been possible to directly demonstrate a role for cell surface carbohydrates in various cellular processes (see refs. 28, 29), further information on the significance of protein-bound carbohydrate to cellular recognition phenomena has been obtained by the use of inhibitors of protein glycosylation. Among these, tunicamycin has been especially valuable because of its specificity and well-characterized mechanism of action, i.e. noncompetitive, irreversible inhibition of $\mathrm{N}$-acetylglucosaminyl pyrophosphoryl dolichol transferase ${ }^{15}$. Studies with tunicamycin have 
been useful in either confirming ${ }^{8.14,27}$ or eliminating 25,32 postulated roles of $\mathrm{N}$-linked glycoproteins in many biological processes. In the present study, both neurite outgrowth and lectin binding were found to be inhibited by tunicamycin treatment of goldfish retinal explants. The effects on neurite outgrowth appeared not to be due to non-specific toxicity, since the inhibition was reversed upon removal of the drug. That a defect in glycosylation was the cause of the reduced outgrowth is indicated by the minimal effects of tunicamycin on protein synthesis (with either $\left[{ }^{3} \mathrm{H}\right]$ proline or $\left[{ }^{3} \mathrm{H}\right]$ leucine as precursor) and the close parallel between inhibition of neuritic outgrowth and of dolichol oligosaccharide synthesis. While the concentrations of TM used here were approximately 10 -fold higher than those found to be effective in muscle cells $\mathrm{s}^{23,24,26}$, adipocytes $^{27}$ or sea urchin embryos ${ }^{14}$, they are similar to or lower than those used in studies of oviduct slices $^{32}$, retina ${ }^{25}$ and myelin ${ }^{31}$. In addition, the relative purity of the various TM preparations is a confounding factor in direct comparisons of dose-response.

The requirement of protein glycosylation for neurite elongation could be a manifestation of any of several possible functions of the protein-bound oligosaccharide. These include adhesion to the substratum, fasciculation of the neurites or maintenance of the structural integrity of the axolemma. There was no obvious effect of tunicamycin on fasciculation in these experiments except that those explants with fewer neurites had thinner fascicles. At the highest dose used, $10 \mu \mathrm{g} / \mathrm{ml}$, deterioration of the neurites was noted. Perhaps this observation, and the growth inhibition at the lower doses of tunicamycin as well, relates to the postulated role of the carbohydrate chain in protecting against proteolysis of glycoproteins ${ }^{24,26}$. In this regard, a preliminary experiment with the protease inhibitor, leupeptin $(0.5 \mathrm{mM})$ showed no reversal of the effects of

\section{REFERENCES}

1 Axelrod, D., Wight, A., Webb, W. and Horwitz, A., Influence of membrane lipids on acetylcholine receptor and lipid probe diffusion in cultured myotube membrane, Biochem., 17 (1978) 3604-3609.

2 Barondes, S. H. (Ed.), Neuronal Recognition. Plenum Press, New York, 1976. tunicamycin. The adhesion of the explants to the polylysine substratum was not altered by tunicamycin, although effects on the adhesivity of the neurites cannot be ruled out. Other possible glycosylationsensitive cellular functions whose disruption might affect neurite growth include membrane transport of nutrients ${ }^{23}$ and axonal transport. Although glycoproteins are prominent constituents of the rapid phase of axonal transport. there has thus far been no report of an effect of glycosylation inhibition on this process.

The reduction in neurite lectin binding capacity following treatment with tunicamycin, although indicating a decrease in axolemmal carbohydrate, does not of itself prove that unglycosylated glycoproteins are being inserted into the neurite membrane. The latter seems likely, however. in view of results in other systems. Thus, although tunicamycin blocked glycosylation, it had no effect on the insertion of rhodopsin into the disk membrane of the rod outer segment ${ }^{25}$ or on association of the $P_{0}$ protein with PNS myelin membrane ${ }^{31}$. The possibilicy remains that the tunicamycin-treated neurite membrane may exhibit an overall deficit in protein concomitant with the decrease in glycoprotein. Nevertheless, these experiments demonstrate that conditions can be obtained wherein a carbohydrate-deficient neurite membrane can be elaborated in vitro and suggest the usefulness of tunicamycin in evaluating the role of cell surface carbohydrate in recognition and synaptic connectivity in other neuronal culture systems

\section{ACKNOWLEDGEMENTS}

This work was supported by NIH Grant NS 13743 to B. W. Agranoff to whom I am grateful for support and encouragement during the course of this investigation.

3 Bonner, W. M. and Laskey, R. A., A film detection method for tritium-labelled proteins and nucleic acids in polyacrylamide gels, Europ. J. Biochem., 46 (1974) 8388.

4 Chambers, J., Forsee, W. T. and Elbein, A. D., Enzymatic transfer of mannose from mannosyl-phosphoryl-polyprenol to lipid-linked oligosaccharides by pig aorta, $J$. hiol. Chem., 252 (1977) 2498-2506

5 Curtino. I. A., Maccioni, H. J, and Caputo. R., Glycor 
proteins and glycolipids of subcellular fractions from bovine retina. Incorporation of mannose and sialic acid, J. Neurochem., 28 (1977) 803-810.

6 Dulbecco, R., Plaque formation and isolation of pure lines with poliomyelitis viruses, J. exp. Med., 99 (1954) 167-199.

7 Dunlop, D. S., Van Elder, W. and Lajtha, A., Measurement of rates of protein synthesis in rat brain slices, $J$. Neurochem., 22 (1974) 821-830.

8 Duskin, D. and Bornstein, P., Changes in surface properties of normal and transformed cells caused by tunicamycin, an inhibitor of protein glycosylation, Proc. nat. Acad. Sci. (U.S.A.), 74 (1977) 3433-3437.

9 Feldman, E. L., Glycoconjugates in the Regenerating Goldfish Visual System, Ph. D. thesis, University of Michigan, 1979.

10 Feldman, E. L., Heacock, A. M. and Agranoff, B. W., Lectin binding in the regenerating goldfish visual system, Neurosci. Abstr., 4 (1978) 531.

11 Heacock, A. M., Biosynthetic requirements for neurite outgrowth in goldfish retina explants, Neurosci. Abstr., 5 (1979) 756.

12 Heacock, A. M., Effects of tunicamycin on neurite outgrowth, glycoconjugate synthesis and lectin binding in goldfish retina explants, Neurosci. Abstr., 6 (1980) 744.

13 Heacock, A. M. and Agranoff, B. W., Clockwise growth of neurites from retinal explants, Science, 198 (1977) 64-66.

14 Heifetz, A. and Lennarz, W. J., Biosynthesis of N-glycosidically linked glycoproteins during gastrulation of sea urchin embryos, J. biol. Chem., 254 (1979) 6119-6127.

15 Heifetz, A., Keenan, R. W. and Elbein, A. D., Mechanism of action of tunicamycin on the UDP-GIcNAc:dolichylphosphate GIcNAc-1-phosphate transferase, Biochem., 18 (1979) 2186-2192.

16 Kean, E. L., Mannosyl transferases of the retina: mannolipid and complex glycan biosynthesis I, Exp. Eye Res., 25 (1977) 405-417.

17 Landreth, G. E. and Agranoff, B. W., Explant culture of adult goldfish retina: effect of prior optic nerve crush, Brain Research, 118 (1976) 299-303.

18 Landreth, G. E. and Agranoff, B. W., Explant culture of adult goldfish retina: a model for the study of CNS regeneration, Brain Research, 161 (1979) 39-53.

19 Lowry, O. H., Rosebrough, N. J., Farr, A. L. and Randall, R. J., Protein measurement with the Folin phenol reagent, J. biol. Chem., 193 (1951) 265-275.

20 Mans, P. J. and Novelli, G. D., Measurement of the incorporation of radioactive amino acids into protein by a filter paper method, Arch. Biochem. Biophys., 94 (1961) 48-53.

21 Margolis, R. K. and Margolis, R. U., Structure and distribution of glycoproteins and glycosaminoglycans. In R. U. Margolis and R. K. Margolis (Eds.), Complex Carbohydrates of Nervous Tissue, Plenum Press, New York, 1979, pp. 45-73.
22 O'Farrell, P. H., High resolution two-dimensional electrophoresis of proteins, J. biol. Chem., 250 (1975) 4007-4021.

23 Olden, K., Pratt, K. M., Jaworski, C. and Yamada, K. M., Evidence for role of glycoprotein carbohydrates in membrane transport: specific inhibition by tunicamycin, Proc. nat. Acad. Sci. (U.S.A.), 76 (1979) 791-795.

24 Olden, K., Law, J., Hunter, V. A., Romain, R. and Parent, J. B., Inhibition of fusion of embryonic muscle cells in culture by tunicamycin is prevented by leupeptin, J. Cell Biol., 88 (1981) 199-204.

25 Plantner, J. J., Poncz, L. and Kean, E. L., Effect of tunicamycin on the glycosylation of rhodopsin, Arch. Biochem. Biophys., 201 (1980) 527-532.

26 Prives, J. M. and Olden, K., Carbohydrate requirement for expression and stability of acetylcholine receptor on the surface of embryonic muscle cells in culture, Proc. nat. Acad. Sci. (U.S.A.), 77 (1980) 5263-5267.

27 Rosen, O. M., Chia, G. H., Fung, C. and Rubin, C. S., Tunicamycin-mediated depletion of insulin receptors in 3T3-Ll adipocytes, J. Cell Physiol., 99 (1979) 37-42.

28 Schmitt, J. W. and Elbein, A. D., Inhibition of protein synthesis also inhibits synthesis of lipid-linked oligosaccharides, J. biol. Chem., 254 (1979) 12291-12294.

29 Sharon, N., Carbohydrates, Sci. Amer., 243 (1980) 90-116.

30 Sharon, N. and Lis, H., Glycoproteins: research booming on long-ignored, ubiquitous compounds, Chem. Eng. News, 59 (1981) 21-44.

31 Smith, M. E., Effects of tunicamycin on glycoprotein synthesis in PNS myelin, Neurosci. Abstr., 6 (1980) 20.

32 Struck, D. K. and Lennarz, W. J., Evidence for participation of saccharide-lipids in the synthesis of the oligosaccharide chain of ovalbumin, J. biol. Chem., 252 (1977) 1007-1013.

33 Takatsuki, A. and Tamura, G., Effect of tunicamycin on the synthesis of macromolecules in cultures of chick embryo fibroblasts infected with Newcastle disease virus, J. Antibiot., 24 (1971) 785-794.

34 Takatsuki, A., Kohno, K. and Tamura, G., Inhibition of biosynthesis of polyisoprenol sugar in chick embryo microsomes by tunicamycin, Agric. Biol. Chem., 39 (1975) 2089-2091.

35 Tkacz, J. S. and Lampen, J. O., Tunicamycin inhibition of polyisoprenyl $\mathrm{N}$-acetyl glucosaminyl pyrophosphate formation in calf liver microsomes, Biochem. Biophys. Res. Commun., 65 (1975) 248-257.

36 Waechter, C. J., Kennedy, J. L. and Harford, J. B., Lipid intermediates in the assembly of membrane-associated glycoproteins in calf brain white matter, Arch. Biochem. Biophys., 174 (1976) 726-737.

37 Waechter, C. J. and Scher, M. G., Biosynthesis of glycoproteins. In R. U. Margolis and R. K. Margolis (Eds.), Complex Carbohydrates of Nervous Tissue, Plenum Press, New York, 1979, pp. 75-102. 